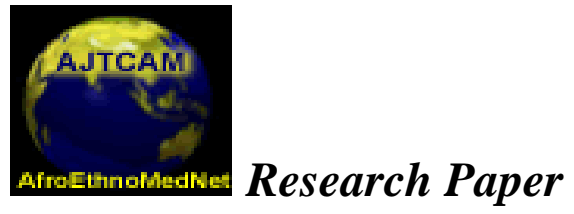

Afr. J. Traditional,

Complementary and Alternative Medicines

www.africanethnomedicines.net

ISSN 0189-6016@2005

\title{
ANTIBACTERIAL, ANTI-INFLAMMATORY AND DIURETIC EFFECT OF FLAVONOIDS FROM MARCHANTIA CONVOLUTA
}

\author{
Jianbo Xiao, Xinyu Jiang, Xiaoqing Chen \\ College of Chemistry and Chemical Engineering, Central South University, Changsha \\ 410083, PR China \\ E-mail: jianbo_xiai@yahoo.com, newfourtharmy@163.com
}

\begin{abstract}
Dried leaves of Marchantia convoluta are largely used to protect livers, and to treat tumefaction of skins in China. Flavonoids from Marchantia convoluta (MCF) were the active components against hepatitis B virus. In this study, the pharmacological properties of MCF consisting of flavonoids determined by HPLC were examined in particular. High dosage of MCF (20 and $40 \mu \mathrm{g} / \mathrm{mL}$ ) could significantly reduce the activity of ALT and AST in the serum of mice with acute hepatic injury caused by $\mathrm{CCl}_{4}$ and increase the contents of TP and ALP. MCF could inhibit the auricle tympanites of mice caused by dimethylbenzene. MCF inhibited obviously colibacillus, tyhoid bacillus, Staphylococcus aureus, bacillus enteritidis, hemolytic streptococci type B and Diplococcus pneumoniae. The results showed that MCF possess distinct effect of antibiosis, anti-inflammation and diuresis in mice.
\end{abstract}

Key words: Marchantia convoluta; Flavonoids; Antibiosis; Antiinflammation; Diuresis

\section{Introduction}

Marchantia plants (Chinese name Di Qian) are well-known traditional Chinese medicinal herbs and have been extensively used to treat tumefaction of skins, protect liver and treat hepatitis and used as antipyretic in countryside (Xia, 1999; Jiang, 1990; Zhu et al., 2004). Marchantia convoluta is ample in Guangxi Zhuang Autonomous District. According to our investigation, flavonoids and sesquiterpenes are the major constituents in Marchantia convoluta. MCF mainly consist of quercetin, luteolin, apigenin and their $O$ - and $C$-glycosides. There are few reports on the bioactivity of 
MCF. In this study, the effects of MCF on antibiosis, anti- inflammation and diuresis in mice were investigated.

Several activities have been attributed to flavonoids, such as radical scavenging (Calzada et al., 1999; Fritz-Niggli et al., 1980; Schmidt et al., 1980), antioxidative (Bohm et al., 1998; Korkina et al., 1997), enzyme inhibitory (Ait-Si-Ali et al., 1998; Jinsart et al., 1992; Le Bail et al., 1998; Young et al., 1999), angiogenesis inhibitory (Cao et al., 1999) and antimalarial activities (Brandao et al., 1997). Of the plant polyphenols, the flavonoids are of particular interest because of their high prevalence in foods such as fruits, vegetables and tea. Hertog et al found that flavonoid intake was inversely related to mortality from coronary heart disease among middle aged Dutch men. Animal and cell culture studies suggested that flavonoids might be against cancers at various sites (Makela et al., 1998; Malaveille et al., 1996).

Phenolic acids and flavonoids are widespread in nature, occurring in all plant families, and are found in considerable quantities in fruits, vegetables, grains, cola, tea, coffee, cocoa, beer, and red wine (Rice-Evans et al., 1996; Skibola et al., 2000). In the United States, the daily dietary intake of flavonoids is estimated to be in the range of 500 to $1,000 \mathrm{mg}$, and even several grams in supplementing diets with flavonoids or flavonoid-containing herbal preparations such as Ginkgo biloba, Pycnogenol 227, or grape seed extract (Skibola et al., 2000). The bioactivities of the dietary phenolic acids and flavonoids are reported to be antioxidative, anti-inflammatory, and anticarcinogenic. Therefore, high consumption of the dietary phenolic acids and flavonoids may have profit for prevention of oxidative damage, cardiovascular diseases, and cancer (Rice-Evans et al., 1996; Skibola et al., 2000).

Acute and chronic inflammatory diseases are still one of the most important health problems in the world. Various agents are adapted to treat inflammatory disorders; their prolonged use often leads to serious adverse reactions such as gastric intolerance, bone marrow depression, water and salt retention. Consequently, development of new anti-inflammatory drugs with low side-effects is still necessary.

\section{Experimental}

\section{General}

Methanol (Chromatographic grade, Jiangsu Hanbon Sci. \& Tech. Co., Ltd), phosphoric acid (Analytical grade, Hanbon), acetonitrile (Chromatographic grade, Hanbon) and acetic acid (Analytical grade, Hanbon) were used for the mobile phase. Quercetin, luteolin, luteolin 7, 3'-di-O-glucuronide, Apigenin 7, 4'-di-O-glucuronide and luteolin 7, 4'-di-O-glucuronide were acquired from Sigma (USA). Apigenin 7-mono-O-glucuronide and apigenin were attained from Chinese Medicine Checking Institute. 


\section{Plant material}

The whole plants of Marchantia convoluta were collected in Shangling City of Guangxi Zhuang Autonomous District in August 2003. The specimen (No 20041364) was identified by Zhou Zi-jing at Biology Department of Guangxi Chinese Medical University. The leaves, after being washed with water and dried in the shade for several days, were powdered.

\section{Extraction, purification and analysis}

The leaves of Marchantia convoluta (280g) were extracted with $80 \%$ ethanol for $24 \mathrm{~h}$ at room temperature. The suspension, after filtration the solvents were removed under vacuum to give a residue, which was separated on silica gel to yield yellow power (5.96g).

HPLC analysis was performed on a Shimadaz LC-2010A LIQUID CHROMATOGRAPH system with a Shimadaz SPD-M10A Diode Array Detector and a Shimadaz Class-vp V6.12 SP4 offline processing system, using a Kromasil RP-C 18 column $(250 \times 4.6 \mathrm{~mm}$ i.d, $5 \mu \mathrm{m}$, Hanbon Science \&Technology Co., Ltd) and methanol-acetonitrile-acetic acid-phosphoric acid- $\mathrm{H}_{2} \mathrm{O}$ (200:100:10:10:200, V/V) as mobile phase. The mobile phase was filtrated through a nylon membrane. Detecting wavelength: $352 \mathrm{~nm}$; Flow rate: $0.60 \mathrm{~mL} / \mathrm{min}$; Sensitivity: 0.05 AUFS. The quantity of injecting sample was $6.0 \mu \mathrm{L}$. The HPLC system was operated at ambient temperature $\left(28 \pm 1{ }^{\circ} \mathrm{C}\right)$.

\section{Animals}

Rats of either sex, weighing 180-200g, were used. They were maintained at $22-28^{\circ} \mathrm{C}, 60-70 \%$ relative humidity, $12 \mathrm{~h}$ dark-light cycle, and fed with standard mouse chow Lipton India and water ad libitum.

\section{Protective effect of MCF against acute hepatic injury of mice caused by $\mathrm{CCl}_{4}$}

A total of 50 rats were divided into high dose of MCF $(0.20 \mathrm{~g} / \mathrm{Kg})$, low dose of MCF $(0.10 \mathrm{~g} / \mathrm{Kg})$, no-treatment control $\left(\mathrm{H}_{2} \mathrm{O}, 20 \mathrm{~mL} / \mathrm{Kg}\right)$, model control $\left(\mathrm{H}_{2} \mathrm{O}, 20\right.$ $\mathrm{mL} / \mathrm{Kg}$ ) and positive control (Dicarboxylate) each 10 for 10 days. Acute liver injury model was induced by injection of $\mathrm{CCl}_{4}$. The levels of serum ALT, AST and contents of $\mathrm{TP}$, ALB were measured $24 \mathrm{~h}$ after the injection of $0.12 \% \mathrm{CCl}_{4}$.

\section{Anti-inflammatory Effect of MCF}

A total 40 male rats were randomly divided into the positive control group (aspirin, $0.2 \mathrm{~g} / \mathrm{Kg})$, no-treatment control group, high dose $(0.2 \mathrm{~g} / \mathrm{Kg})$ and low dose group (0.1 
$\mathrm{g} / \mathrm{Kg}$ ) each 10 for 7 days. The weigh of ear was obtained after dimethylbenzene was dropped on the ears of rats on the $7^{\text {th }}$ day.

\section{Diuretic activity of MCF}

The test was performed according to the Lipschitz test on male rats. The animals, fasted and deprived of water for $18 \mathrm{~h}$ prior to the experiment, were divided in four groups with 10 rats each. The first group of animals, serving as control, received normal saline (25 ml/kg, p. o.); the second group received urea (750 mg/ kg, p. o.) in saline as a standard; the third and fourth groups received MCF at doses of 100 and 200 $\mathrm{mg} / \mathrm{kg}$ in saline, respectively. Immediately after dosing, the animals were separately placed in cages suitable for collection of urine in graduated measuring cylinders. Urines were collected for $6 \mathrm{~h}$ while animals were deprived of food and water. Urine volume concentrations were determined. All the experiments were performed under standard conditions of temperature, light, humidity and noise (Sheth et al., 1972). The results were statistically analysed by Student's t -test.

\section{In vitro antibacterical effects of MCF}

Double dilution and quantitative methods for the drug mutual action were used. Salmonella typhi, Staphylococcus aureus, Pneumococcus, Streptococcus pyogenes, Bacillus enteritidis, Escherichia coli, Candida albicans and Pseudomonas aeruginosa were used in this study.

\section{Statistical analysis}

The results are expressed as Mean \pm S.E.M. The Student 's t test was used for comparison vs. the data of the control groups. Differences with $\mathrm{P}<0.05$ were considered statistically significant.

\section{Results}

\section{Analysis of MCF}

\section{Determination of total flavonoids}

The content of total flavonoids was determined through visible spectrophotometer (Zhu et al., 2004). By studying the factors that affected the determination, the optimal conditions for this experiment were found as follows: $\mathrm{NaNO}_{2}-\mathrm{AlCl}_{3}$, color-developing agent; $15 \mathrm{~min}$, color time; 525nm, wavelength. The data of the content and absorbance formed a standard curve, namely $Y=-0.0153+0.03003 X$; the recovery of the samples was $94.61 \%$ to $101.59 \%$. The content of total flavonoid in Marchantia convoluta is 
$1.90 \%$. The content of total flavonoids of MCF is $96.35 \%$.

\section{HPLC analysis of MCF}

HPLC was used to quantify individual flavonoid by using internal reference. Figure 1 is the HPLC spectrum of MCF. Figure 1. HPLC display of flavonoids peaks in MCF. Peak identifications: $\quad 1$. Luteolin 7, 4'-di-Oglucuronide; $\quad 2$. Apigenin 7, 4'-di-O-glucuronide; 5. Apigenin-7-O- $\beta$-D-glucuronide; 6.Quercetin; 7. Luteolin; 8. Apigenin; 3, 4,9 and 10 were not indentified. A Kromasil RP-C18 column $(250 \times 4.6 \mathrm{~mm}$ i.d, $5 \mu \mathrm{m})$ was used. Mobile phase:methanol-acetonitrile-acetic

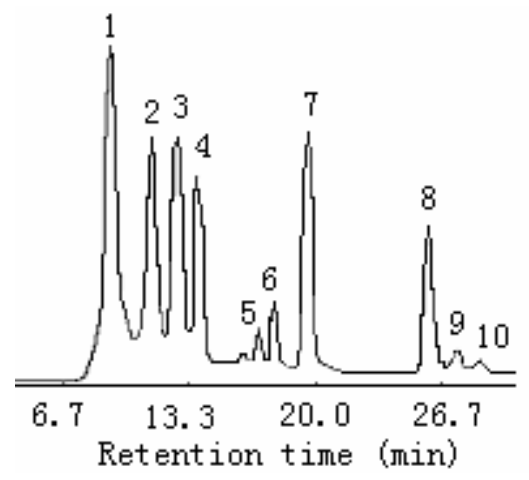
acid- phosphoric acid-H2O (200:100:10:10:200,V/V); Detecting wavelength: $352 \mathrm{~nm}$; Flow: $0.60 \mathrm{~mL} / \mathrm{min}$; Sensitivity:0.05 AUFS; Quantity of injecting sample: $6.0 \mu \mathrm{L}$.

It can be seen, that MCF consist of quercetin, luteolin, apigenin and their O-glycosides.

\section{Protective effect of MCF against acute hepatic injury of mice caused by $\mathbf{C C l}_{4}$}

High dose of MCF $(0.20 \mathrm{~g} / \mathrm{Kg})$ and positive control (Dicarboxylate) can decrease levels of serum ALT and AST and increase contents of TP and ALB obviously. Low dose of MCF $(0.10 \mathrm{~g} / \mathrm{Kg})$ can decrease levels of serum ALT and AST, but not largely P $<0.05$ (Figure 2 and Figure 3).

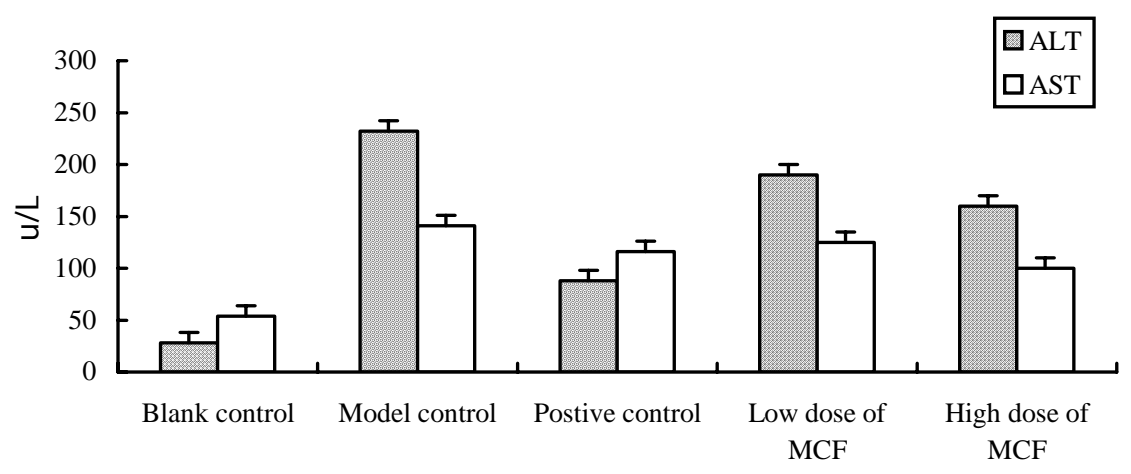

Figure 2: Effect of MCF on ALT and AST of mice injured by $\mathrm{CCl}_{4}(\mathrm{X} \pm \mathrm{S}, \mathrm{n}=10)$ vs blank control: $\mathrm{P}<0.05 ; \mathrm{P}<0.01$; $\mathrm{P}<0.01$ vs model control: $\mathrm{P}<0.05 ; \mathrm{P}<0.01 ; \mathrm{P}<0.01$ 


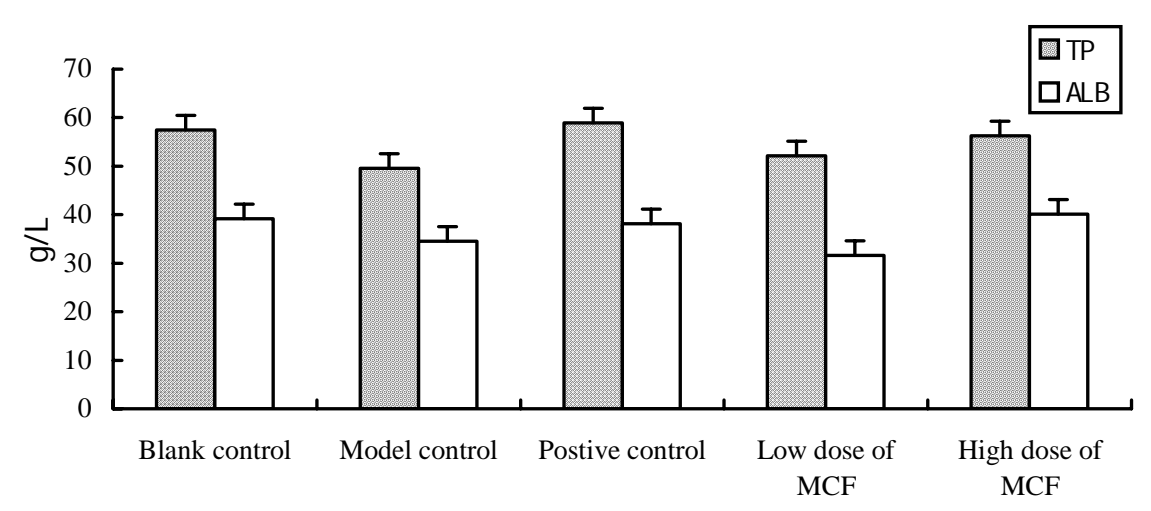

Figure 3: Effect of MCF on TP and ALB of mice injured by $\mathrm{CCl}_{4}(\mathrm{X} \pm \mathrm{S}, \mathrm{n}=10)$ vs blank control: $\mathrm{P}<0.05 ; \mathrm{P}<0.01 ; \mathrm{P}<0.01$ vs model control: $\mathrm{P}<0.05 ; \mathrm{P}<0.01 ; \mathrm{P}<0.01$

As a result of inflammation induced by $\mathrm{CCl}_{4}$, the level of serum transaminase, AST and ALT were increased. Accordingly, the assessment of the level of AST and ALT provided a good and simple tool to measure the anti-inflammatory activity of the target compounds (Shet et al., 1972).

As shown in Figure 2, plasma ALT activity of group given high dose of MCF was significantly lower than that of control group, while AST activity was not significantly affected.

\section{Anti-inflammatory effect of MCF}

The results of anti-inflammatory activity of MCF are reported in Table 1 . High dose of MCF $(0.20 \mathrm{~g} / \mathrm{Kg})$ and the positive control group (aspirin, $0.2 \mathrm{~g} / \mathrm{Kg})$ can inhibit the auricle tympanites of mice caused by dimethylbenzene. Statistical analysis showed that the inhibitory effects of MCF are significantly different from control group at all the concentrations tested. The results showed that the anti-inflammatory effect of MCF $(0.20 \mathrm{~g} / \mathrm{Kg})$ was similar to that of positive control group (aspirin, $0.2 \mathrm{~g} / \mathrm{Kg})$. The inhibition rate of MCF for high dose on auricle tympanites of mice caused by dimethylbenzene was 21.8\%, whereas the positive control group (aspirin, $0.2 \mathrm{~g} / \mathrm{Kg}$ ) was $32.1 \%$. Effect of low dose of MCF $(0.10 \mathrm{~g} / \mathrm{Kg})$ was not obvious $(\mathrm{P}<0.05)$. These results showed that MCF had anti-inflammatory effect.

\section{In vitro antibacterial effects of MCF}

Double dilution and quantitative methods for the drug mutual action were used. MCF inhibited Salmonella typhi, Staphylococcus aureus, Pneumococcus, Streptococcus pyogenes, Bacillus enteritidis and obviously Escherichia coli. But it had no effect on $P$. aeruginosa, Candida albicans and Pseudomonas aeruginosa. The result is shown in Table 2. 
Table 1: Effect of MCF on auricle tympanites of mice caused by dimethylbenzene

$$
(n=10)
$$

\begin{tabular}{cccc}
\hline Testing batch & Dose g/kg & weigh of ears $(\mathrm{mg}, \bar{x} \pm \mathrm{s})$ & Inhibit rate (\%) \\
\hline No-treatment & & $23.4 \pm 4.0$ & \\
control & 0.2 & $15.9 \pm 5.3^{* *}$ & 32.1 \\
Aspirin & 0.2 & $18.3 \pm 2.9^{* *}$ & 21.8 \\
High dose of MCF & 0.1 & $20.3 \pm 4.3^{*}$ & 13.2 \\
Low dose of MCF & \multicolumn{2}{c}{}
\end{tabular}

Table 2: Antibacterial activity of $\mathrm{MCF}^{\mathrm{a}}$

\begin{tabular}{ccc}
\hline Strain & No. & MCF $(\mathrm{mg} / \mathrm{mL})$ \\
\hline Salmonella typhi & 20024 & 0.625 \\
Staphylococcus aureus & 2005 & 0.625 \\
Diplococcus pneumoniae & $31108-4$ & 1.25 \\
Streptococcus Pyogenes & 200315 & 2.5 \\
Bacillus enteritidis & 50041 & 2.5 \\
Escherichia coli & 7424 & 2.5 \\
Bacillus dysenteriae & 8144 & No effect \\
Candida albicans & 0737 & No effect \\
Pseudomonas aeruginosa & 4256 & No effect \\
\hline
\end{tabular}

a Values are the means of three replicates.

\section{Diuretic effect of MCF on rats}

MCF and positive control group had diuretic effect on rats after given drugs for $6 \mathrm{~h}$ (Figure 4). Treatment with MCF (100 and $200 \mathrm{mg} / \mathrm{kg}$, p. o.) showed significant increase of the volume of urine at both dose levels. The obtained effect of high dose of MCF (200 mg/kg, p.o) was comparable to that of urea (750 mg $/ \mathrm{kg}$, p.o.) .

\section{Conclusion}

Flavonoids from Marchantia convoluta reduced distinctively the activity of ALT and AST in the serum of mice with acute hepatic injury caused by $\mathrm{CCl}_{4}$ and increased the contents of TP and ALP. MCF could inhibit the auricle tympanites of mice caused by dimethylbenzene; MCF inhibited obviously proliferation of colibacillus, tyhoid bacillus, 


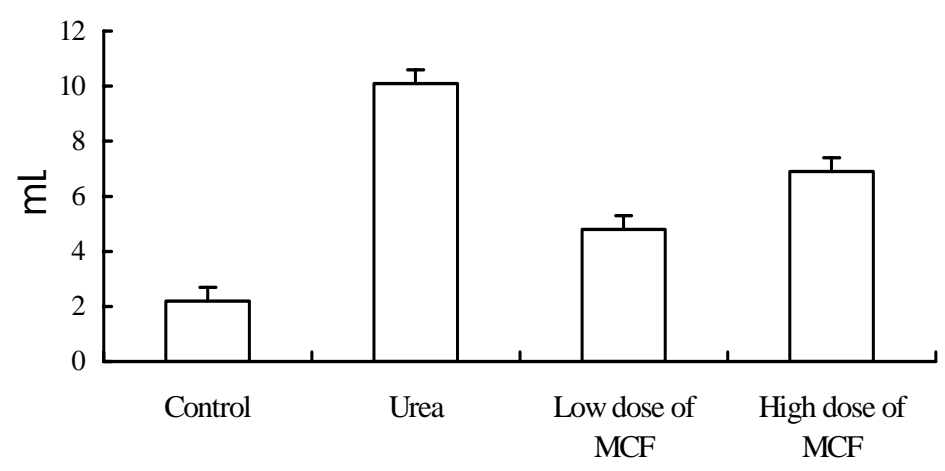

Figure 4: Diuretic effect of MCF on rats

Staphylococcus aureus, Bacillus enteritidis, haemolytic streptococci type B and Diplococcus pneumoniae. The present investigation clearly showed that MCF caused a significant increase in diuretic activity. Although these results provide a support for the traditional uses of $M$. convoluta aerial parts, further studies are necessary to evaluate its safety and modes of action.

\section{References}

1. Ait-Si-Ali, S, Ramirez, S. and Barre, F. X. (1998). Histone acetyl transferase activity of CBP is controlled by cycle-dependent kinases and oncoprotein E1A. Nature 396:184-186.

2. Bohm, H., Boeing, H. and Hempel, J. (1998). Flavonols, flavone and anthocyanins as natural antioxidants of food and their possible role in the prevention of chronic diseases. (German).Z Ernährungswiss 37:147-163.

3. Brandao, M. G., Krettli, A. U. and Soares, L. S. (1997). Antimalarial activity of extracts and fractions from Bidens pilosa and other Bidens species (Asteraceae) correlated with the presence of acetylene and flavonoid compounds. J Ethnopharmacol 57:131-138

4. Cao, Y., and Cao, R. (1999). Angiogenesis inhibited by drinking tea. Nature 398:381.

5. Calzada, F., Meckes, M. and Cedillo-Rivera, R. (1999). Antiamoebic and antigiardial activity of plant flavonoids. Planta Med 65:78-80.

6. Fritz-Niggli, H. and Frohlich, E. (1980). Reduction of radiation-inducedearly skin damage (mouse foot) by O-(hydroxyethyl)-rutoside. (German) ROFO Fortschr Geb Rontgenstr Nuklearmed (133) 316-321.

7. JiangSu Institute of Botany. XinHua Compendium of Herbage. Shanghai: Shanghai Liteature Press for Science and Tenchnology, 1990. p. 766.

8. Jinsart, W, Ternai, B. and Polya, G. (1992). M.Inhibition of rat liver cyclic AMP-dependent protein kinase by flavonoids. Biol Chem Hoppe Seyler 373:205-211. 
9. Korkina, L. G. and Afanas'ev, I. B.(1997). Antioxidant and chelating properties of flavonoids. Adv Pharmacol 38: 151- 163.

10. Le Bail, J., Laroche, C., Marre-Fournier, T. and and Habrioux, G. (1998). Aromatase and 17beta-hydroxysteroid dehydrogenase inhibition by flavonoids. Cancer Lett 133:101-106

11. Makela, S, Poutanen, M., Kostian, M. L., Lehtimaki, N., Strauss, L., Santti, R. and Vihko, R., (1998). Inhibition of 17beta-hydroxysteroid oxidoreductase by flavonoids in breast and prostate cancer cells. Proc Soc Exp Biol Med 217:310-316.

12. Malaveille, C., Hautefeuille, A., Pignatelli, B., Talaska, G., Vineis, P., and Bartsch, H., (1996). Dietary phenolics as anti-mutagens and inhibitors of tobacco-related DNA adduction in the uroth-elium of smokers. Carcinogenesis, 17: 2193-2200.

13. Rice-Evans, C. A., Miller, N. J. and Paganga, G. (1996). Structure-antioxidant activity relationships of flavonoids and phenolic acids. Free Radic Biol Med 20: 933-956.

14. Schmidt, H., Hampel, C. M., Schmidt, G., Riess, E., and Rodel, C. (1980). Double-blind trial of the effect of a propolis-containing mouthwash on inflamed and healthy gingiva. (German). Stomat DDR 30: 491-497.

15. Skibola, C. F. and Smith, M. T. (2000). Potential health impacts of excessive flavonoid intake. Free Radic Biol Med 29: 375-383.

16. Sheth, U. K., Dadkar, N. K. and Kamat, U. G..(1972). Selected Topics in Experimental harmacology. Kothari Book Depot, Bombay, p164

17. Xia, Z. N. (1999). CiHai. Shanghai: Shanghai Literature Press for Science and Tenchnology, p. 639.

18. Xiao, J. B., Cao, H., Zhong, S. A. and Zhu, H. (2004).Isolation and identification of flavonoids from Marchantia convoluta.Chinese Traditional and Herbal Drugs Suppl: 43-44

19. Young, J. F., Nielsen, S. E. and Haraldsdottir, J. (1999). Effect of fruit juice intake on urinary quercetin excretion and biomarkers of antioxidative status. Am. J. Clin. Nutr 69: 87-94.

20. Zhu, H., Xiao, J. B., Zhong, S. A. Zhou C. S. and Huang H. B (2004). Study on leaching and purifying method of flavones from Marchanta polymorpha. Chemistry Industry Forest Products 24: 69-72.

21. Zhu, H, Xiao, J. B., Zhong, S. A., Zhou C. S. and Ren X. L. (2004). Determination of Flavonoids in Marchantia Poymorpha.Chinese J. Spectrocopy Laboratory 21:373-376 